\title{
Research Paper \\ Identifying Structural Suitability Components of Aged-friendly Mosques in Iran: A Qualitative Study
}

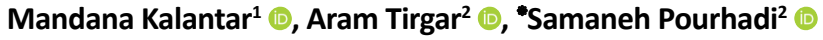

1. Student Research Committee, Babol University of Medical Sciences, Babol, Iran.

2. Social Determinants of Health Research (SDH) Center, Health Research Institute, Babol University of Medical Sciences, Babol, Iran.

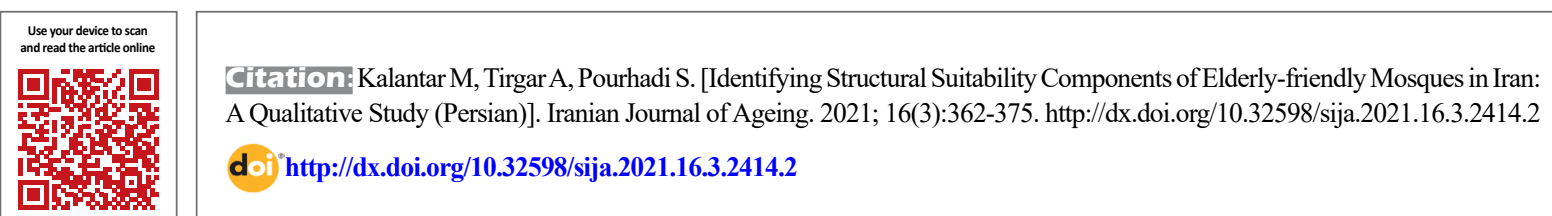

Received: 24 Dec 2020 Accepted: 09 Mar 2021 Available Online: 01 Oct 2021

Keywords:

Aged, Structure, Viewpoint, Assessment, Mosque, Qualitative research

\section{A B S T RACT}

Objectives One way to improve the social participation of the elderly is to pay attention to environmental adaptation, and ensure safety and independence of them in places they use. Due to the rapid growth of the aging population in Iran and considering the important role of mosques as one of the main religiousspiritual places for the elderly, conducting studies to determine the structural suitability components of the mosques in terms of geriatrics and ergonomics are necessary. Therefore, the present study aims to identify the structural suitability components of elderly-friendly mosques in Iran.

Methods \& Materials This is a qualitative study using the content analysis method conducted in 2020. Participants were 18 eligible older adults (13 women and 5 men) aged 61-72 years (Mean \pm SD age=66.33 \pm 2.99 ) attended the mosques of Babol city who had the ability to communicate effectively and the willingness to participate in the study. The mosques were selected based on the geographical distribution (in north, south, east, and west). The data collection method was in-depth and semi-structured interviews, which continued until data saturation. Each interview was transcribed and analyzed step by step according to Kvale's method. Results The extracted data were divided into 5 main categories and 18 subcategories as the structural suitability components of elderly-friendly mosques. Extracted main categories included: Outdoor Environment, Indoor Environment, Equipment, Basic Welfare Amenities, and Internal Facilities.

Conclusion The identified components can help find and prioritize the needs and select the type of interventions to be conducted in the mosque according to the characteristics of the elderly.

\section{Extended Abstract}

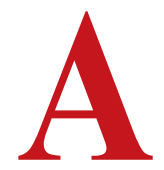

\section{Introduction}

ccording to the United Nations, a significant proportion of the elderly population lives in developing countries including Iran that are not prepared to deal with the phenomenon of aging and its social and economic health consequences [1, 2]. Given Iran's current young population, it is expected that in the next 50 years, it will be one of the countries with a large percentage of older adults [3]. Considering the important role of mosques as one of the main religious-spiritual bases for social, psychological and physical issues of the elderly in Iran, as well as the growth of the Iranian elderly population in recent years and not paying attention to the specific designs of mosques for this population, it seems that identifying and removing

\footnotetext{
* Corresponding Author:
}

Samaneh Pourhadi, PhD.

Address: Social Determinants of Health Research (SDH) Center, Health Research Institute, Babol University of Medical Sciences, Babol, Iran.

Tel: +98 (113) 2190101

E-mail: samaneh.pourhadi@gmail.com 
barriers in mosques to the presence of the elderly is necessary. In this regard, the aim of the present study is to identify the components of structural suitability for elderly-friendly mosques through a qualitative approach. The approach was selected because it emphasizes on observing phenomena naturally without any presumptions and its results can be used to explain the components and create new theories.

\section{Methods}

This is a qualitative study using a conventional content analysis method. It obtained an ethical approval from the Ethics Committee of Babol University of Medical Sciences (Code: IR.MUBABOL.HRI.REC.1398.324). The study population consisted of the elderly attended the mosques of Babol city, Iran aged $>60$ years. Mosques were selected based on geographical distribution and sampling was done using a purposive technique continued until data saturation from January to May 2020. In this regard, 18 eligible older adults were selected. The inclusion criteria were regular and weekly attendance at mosques to perform religious duties, being able to transfer experiences about the subject, and willingness to participate in the study.

In-depth semi-structured interviews were used for collecting data by semi-open-ended questions such as: "What are the structural barriers and problems that you and other seniors have in using the mosque environment?" Exploratory questions were also used to deepen the interview and extract more information. The interviews were conducted individually and face to face inside the mosques. The duration of each interview was 20-40 minutes. The interviews continued until the information was saturated. The recorded interviews were transcribed verbatim and analyzed using continuous comparison and content analysis.

Table 1. Extracted categories and subcategories

\begin{tabular}{|c|c|}
\hline Categories & Subcategories \\
\hline Outdoor environment & $\begin{array}{c}\text { Accessibility } \\
\text { Access to parking lot } \\
\text { Access to public transportation }\end{array}$ \\
\hline Indoor environment & $\begin{array}{l}\text { Landscaping } \\
\text { Gender inequality in the interior space division } \\
\text { Interior space dimensions } \\
\text { Partitioning interior space } \\
\text { Decorating and beautifying the interior space }\end{array}$ \\
\hline Basic welfare amenities & $\begin{array}{c}\text { Sound system } \\
\text { Air conditioning system } \\
\text { Light and brightness } \\
\text { Cooling and heating systems }\end{array}$ \\
\hline Equipment & $\begin{array}{l}\text { Adaptation of internal requirements } \\
\text { safety }\end{array}$ \\
\hline Internal facilities & $\begin{array}{l}\text { Communication facilities between storeys } \\
\text { Toilet } \\
\text { Ablution house } \\
\text { Catering services }\end{array}$ \\
\hline
\end{tabular}




\section{Results}

In this study, 18 older people aged 61-72 years (Mean \pm SD age $=66.33 \pm 2.99$ years) participated, of whom 13 were women and 17 were married. After carefully reading the interviews and separating the conceptual units as code, 520 initial codes were obtained. By continuous comparison and data analysis, these codes were divided into 18 subcategories, which finally resulted in 5 main categories presented in Table 1.

Outdoor environment: this category included following subcategories: Accessibility, Access to parking lot, and Access to public transportation. Indoor environment: this category included following subcategories: Landscaping, Gender inequality in the interior space division, Interior space dimensions, Partitioning interior space, and Decorating and beautifying the interior space. Having basic welfare amenities: this category included following subcategories: Sound system Air, conditioning system, Light and brightness, and Cooling and heating systems. Equipment: this category included following subcategories: Adaptation of internal requirements, and safety. Internal facilities: this category included following subcategories: Communication facilities between storeys, Toilet, Ablution house, and Catering services

\section{Discussion and Conclusion}

The purpose of this study was to find the structural factors of mosques according to the perspective of the elderly in Babol. The results revealed five factors of the outdoor environment, indoor environment, basic welfare amenities, equipment, and internal facilities. The identified factors can help identify and prioritize needs and select the type of interventions in the mosques appropriate to the characteristics of the elderly. Mosques are a suitable place for the social participation of the elderly and the provision of their spiritual desires and needs. Hence, their structures should have a favorable design for the elderly. The results of this study can pave the way for future studies on the structural factors of elderly-friendly mosques. A similar study can be conducted in other cities of Iran to confirm and complete the results by combination with quantitative methods to obtain other aspects that might not be detectable due to the limited location of the study or the specific cultures of the study city.

\section{Ethical Considerations}

\section{Compliance with ethical guidelines}

The study was approved by the Ethics Committee of Babol University of Medical Sciences (Code: IR.MUBABOL. HRI.REC.1398.324).

\section{Funding}

This study was extracted from the MSc. thesis of the first author at the Student Research Committee, Babol University of Medical Sciences, Babol.

\section{Authors' contributions}

Conceptualization: Aram Tirgar; Methodology, draft writing: Samaneh Pourhadi, Mandana Kalantar; Date analysis: Samaneh Pourhadi; Final editor: All authors.

\section{Conflicts of interest}

The authors declared no conflict of interest.

\section{Acknowledgements}

The authors would like to thank the Vice-Chancellor for Research of Babol University of Medical Sciences and the seniors participated in the study for their support and cooperation. 


\title{
تبيين مؤلفهایى ثناسب ساختارى مساجد دوستدار سالمند: يك مطالعه كيفى
}

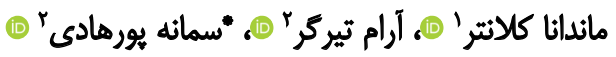

1. ا.مركز تحقيقات دانشجويى، دانشكاه علوم يزشكى بابل، بابل، ايران.

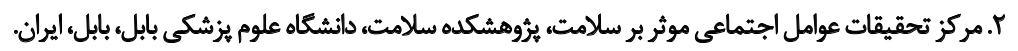

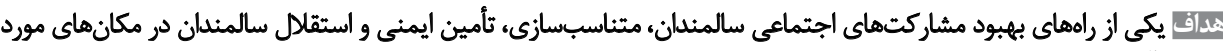

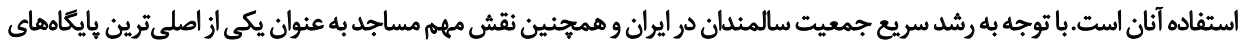

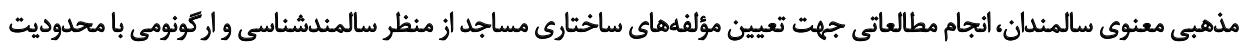

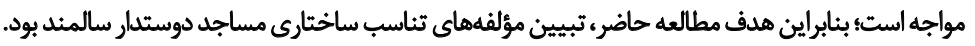

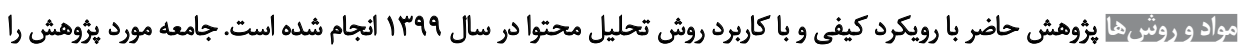

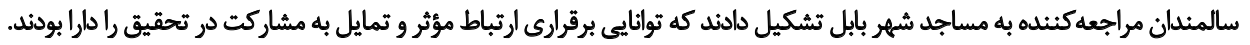

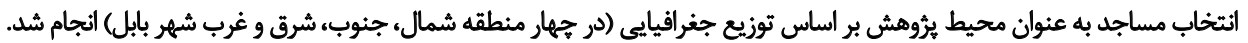

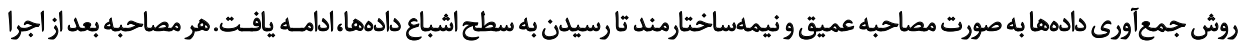

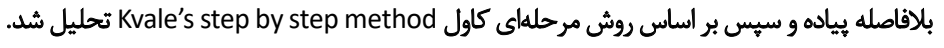

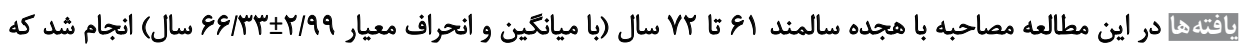

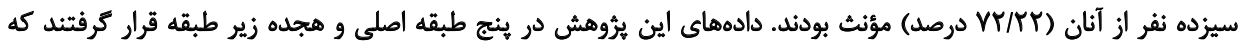

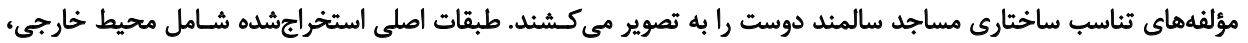

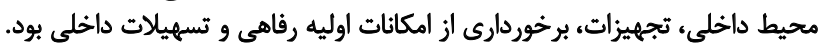

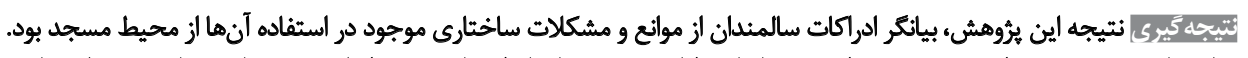

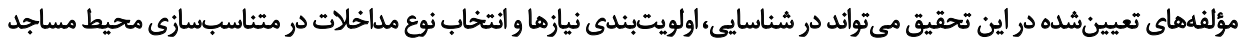

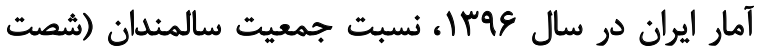

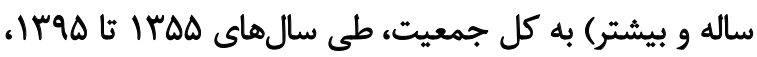

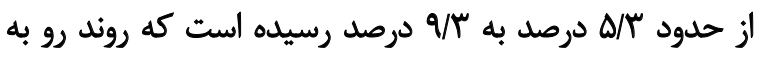

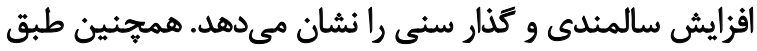

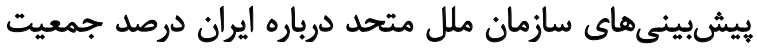

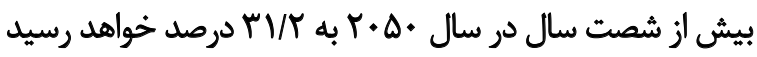

سالمندى، دوره حساسى از زندكى است و توجه به مسائل و

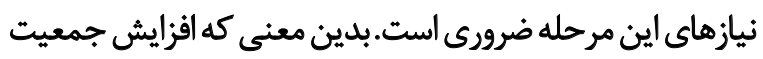

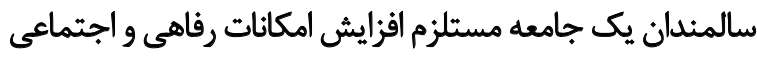

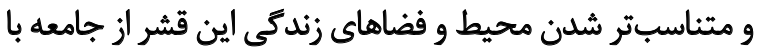

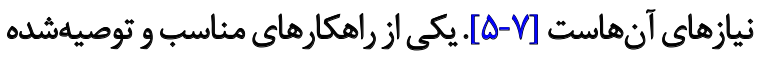

dolato

بر اساس كزارش سازمان ملل متحد' سهم قابل توجهى از

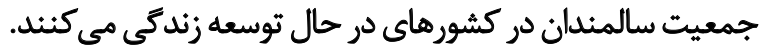

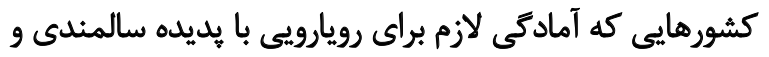

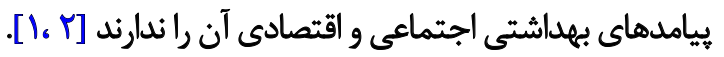

در اين راستا كشور ايران نيز از اين قاعده مستثنا نيست و با بان

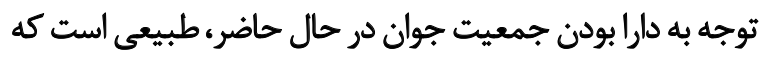

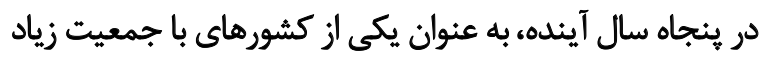

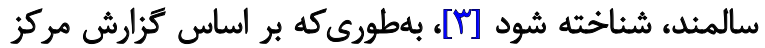

1. United Nations 
تلقى مىشوند. در ايران نيز هماند ساير كشورهاى اسلامي، يكى از مكانهايى كه سالمندان بيشترين حضور راند ادر آن دارند،

مساجد است [10].

بر اساس مباحث علم سالمندشناسى، يكى از راههاى بهبود

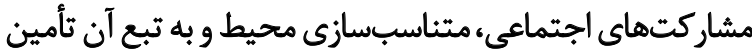

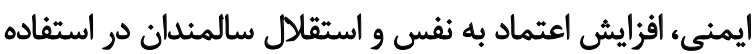

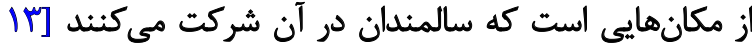

.[9. 11]。

در اين خصوص اكرجه در سال هاى كذّشته، مطالعات داخلى در مورد تبيين معيارهاي تناسب ساختارى مرتبط بإي باس سالمندان

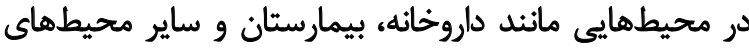

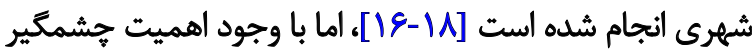

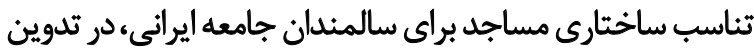

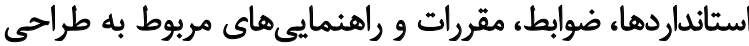

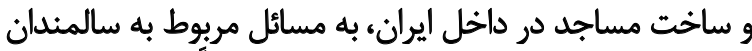

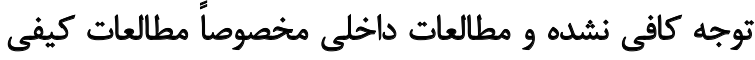

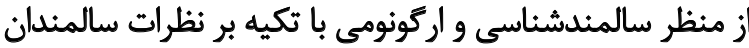
داراى محدوديت است.

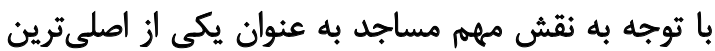

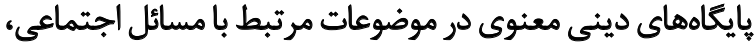

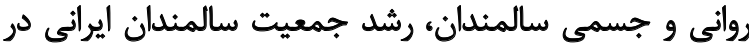

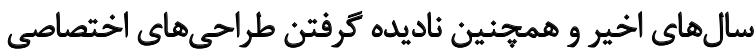

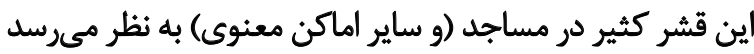

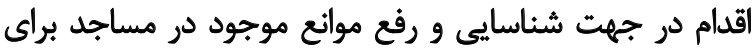
حضور سالمندان، امرى لازم و ضرورى است مون.

در همين راستا، هدف مطالعه حاضر، تبيين مؤلفههاى تناسب

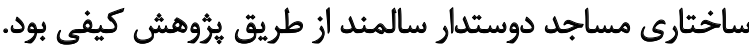

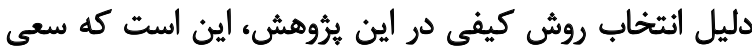

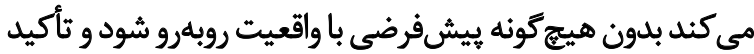

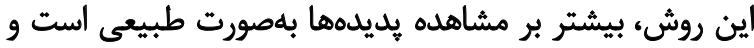

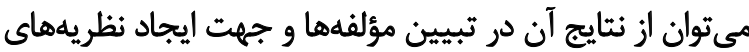

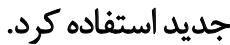

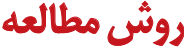

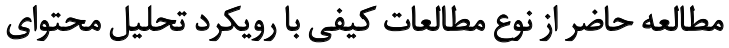

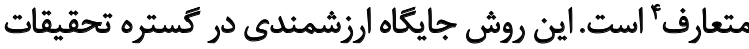

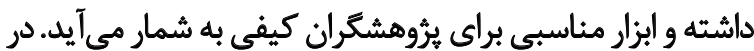

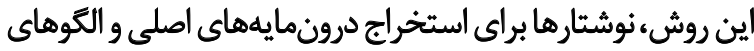

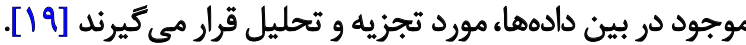
در اين مطالعه، جامعه مورد يُروهش را سالمندان مراجعه كنتده

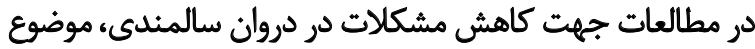

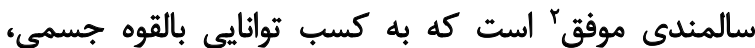

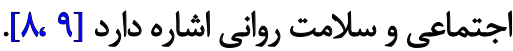

بر اساس مباحث مرثبط با سالمندى، موضوع "ادركيرى و

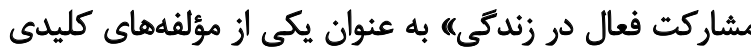

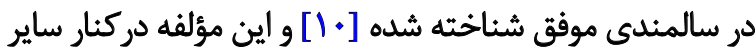

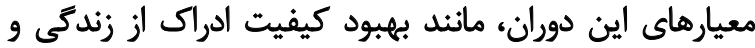
محيط عينى، در ارتباط مستقيم با حضور سالمند در محيطهائ إنها

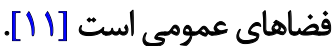

بر اساس رويكرد سازمان بهداشت جهانيّ توزيع خدمات

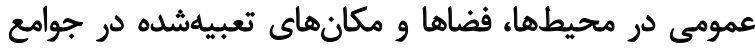

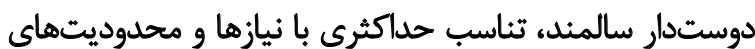

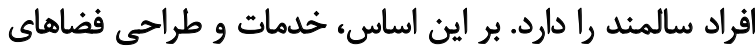

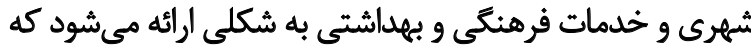

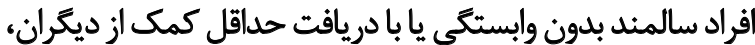

بتوانند از اين امكانات بهرهمند شوند [111].

علاوه بر اين، در اين مكانها توجه به نيازهاى افراد سالمند

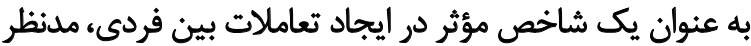

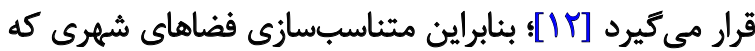

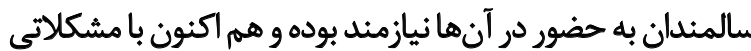

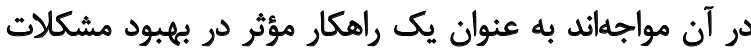

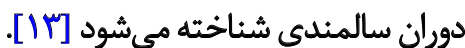
يكى از مكانهاى نيازمند متناسبسازى براي استفاده بهينه

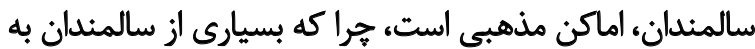

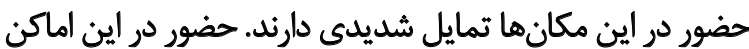
باعث حفظ ارتباطات اجتماعى، انجام فعاليتهائ دارئ داوطلبانيانه.

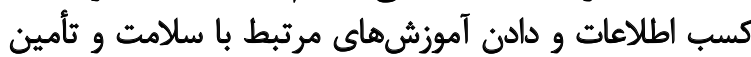

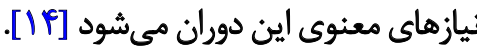
رفتارها و نكرشهاى مذهبى، تأثير مثبتى بر معنادار كردن

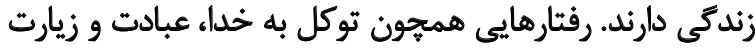

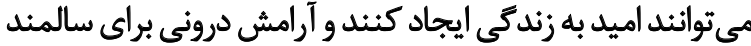

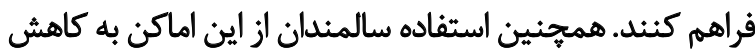

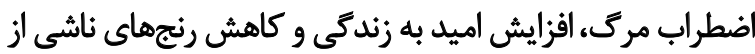

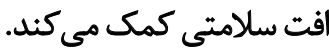

تحقيقات نشان داده است سالمندان بيش از افراد جوان بان بارئ

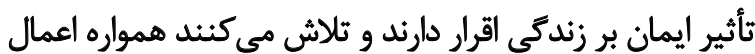

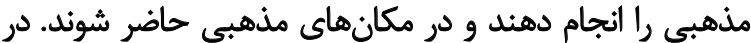

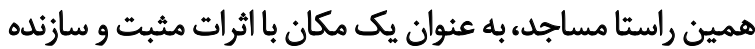
در خصوص سلامت جسمى، روانى، اجتماعى و معنوى سالمندان

3. World Health Organization 
شد. به عنوان مثال، سؤال محورى از سالمند: هاموانع و مشكلات

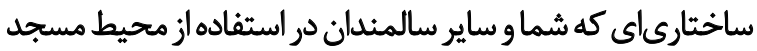

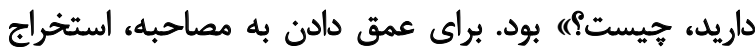

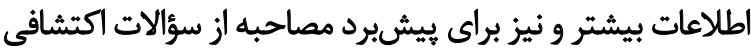

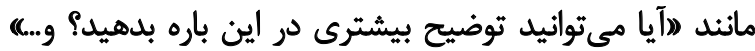

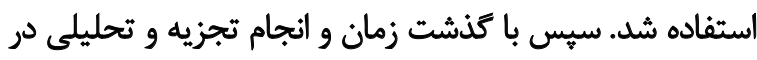

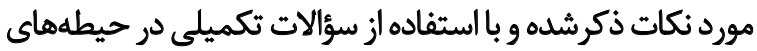

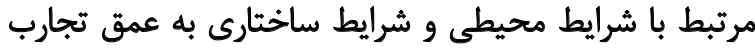

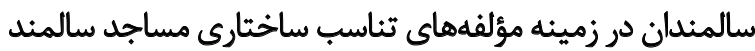

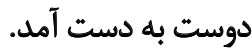

بر اين اساس، مكالمات ضبطشده در مصاحبهها كلمه به كلمه

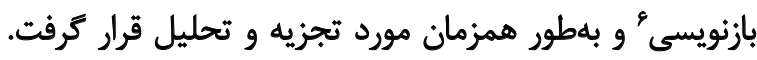

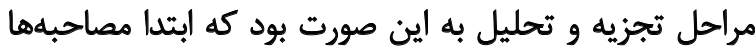

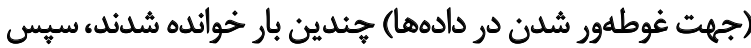

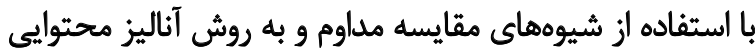

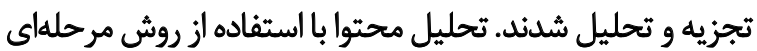

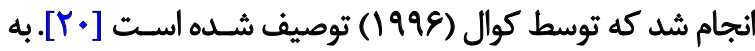

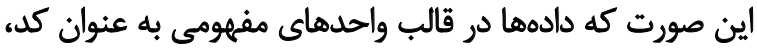

زيرطبقه و طبقه دستهبندى شدند ادند [19].

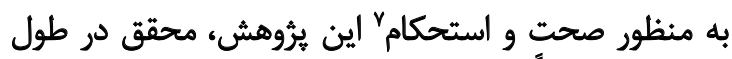

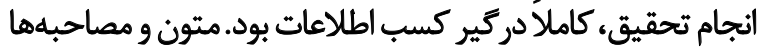

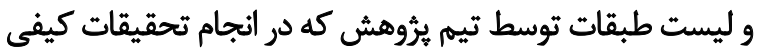

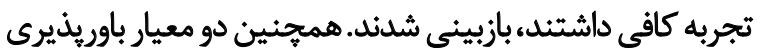

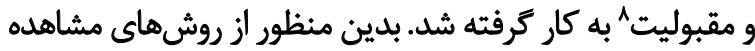

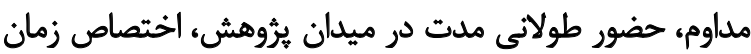

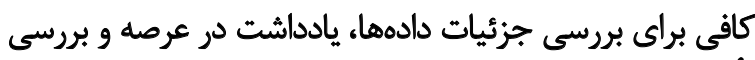

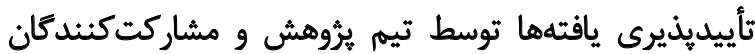

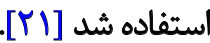

يافتهها

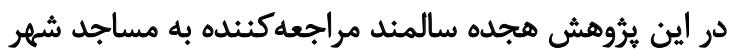

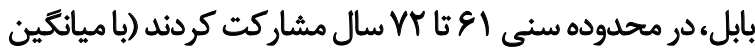

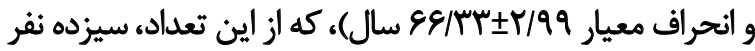

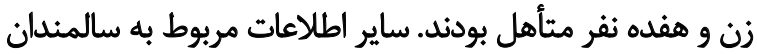

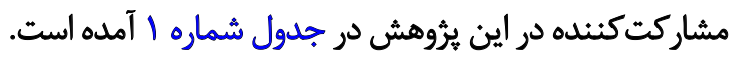

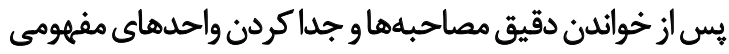

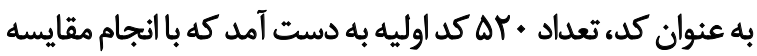

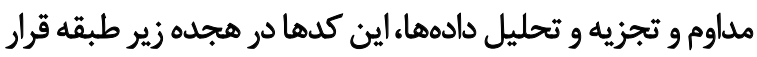

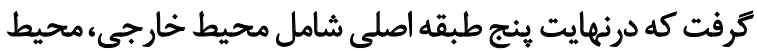

6. Transcript

7. Trustworthiness

8. Credibility
به مساجد شهر بابل با سن بيش از شصت سال (بر اساس تعريف

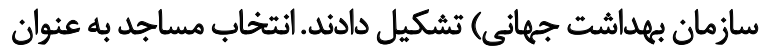

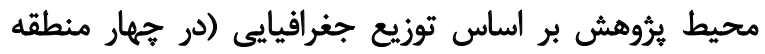

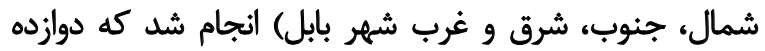

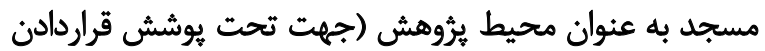

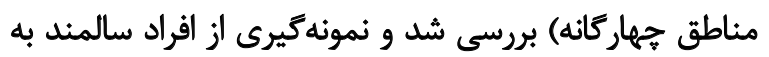

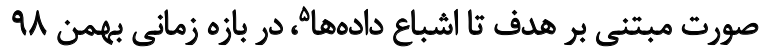

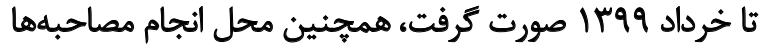
در محوطه داخلى مسجد بود.

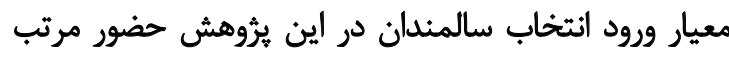

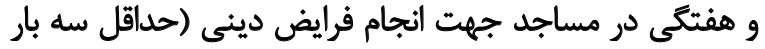

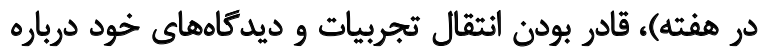

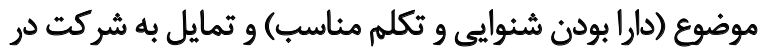

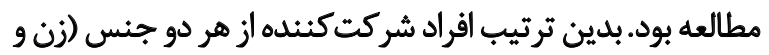

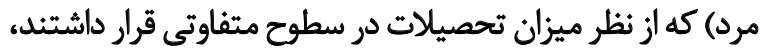

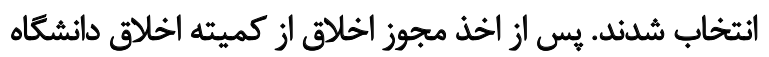
علوم يزشكى بابل (IR.MUBABOL.HRI.REC.1398.324) اخدانيه

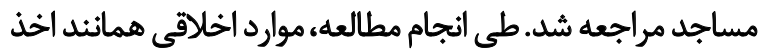

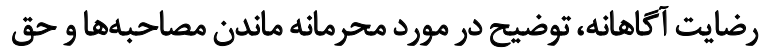

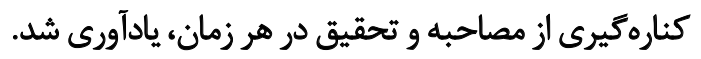
در اين مطالعه، فرايند نمونه كيرى و مصاحبه ثا اشباع دادهها

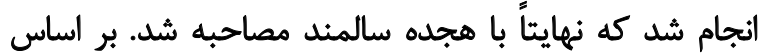

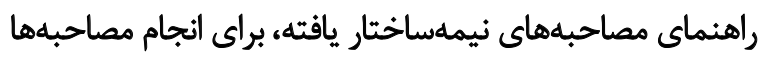

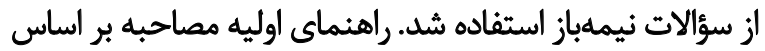

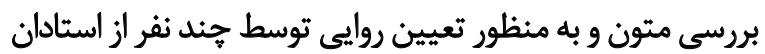

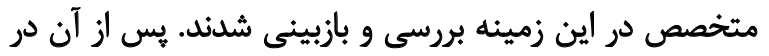

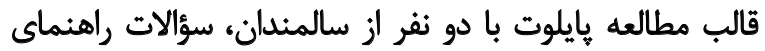
مصاحبه تصحيح و راهنماى يرسش ترى اصلى تلى تهيه شد. در مسير مطالعه نيز، برحسب ضرورت، سؤالات بازنكرى شديند.

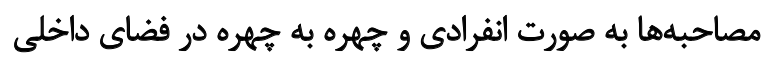

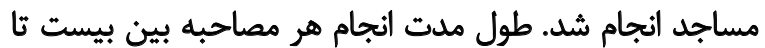

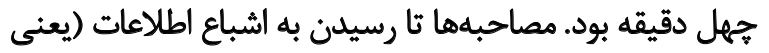

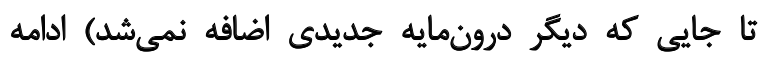

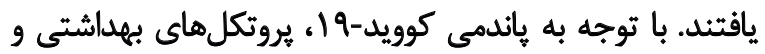

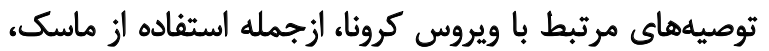

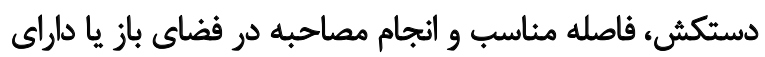

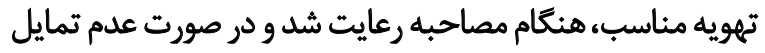

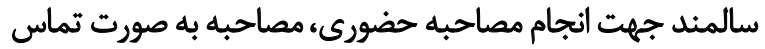

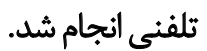

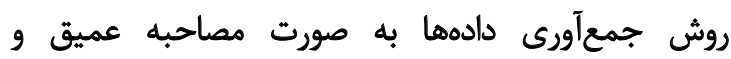
نيمهساختارمند بود و سؤالات بر مبناى سؤال كلى تحقيق طرح

5. Data Saturation 
جدول ا. مشخصات جمعيتشناختى سالمندان مشاركتكنينده

\begin{tabular}{|c|c|c|c|c|c|c|}
\hline محل & تحصياتث & وضعيث ثأهل & شُغل & ين & جنس & كد \\
\hline مسجد شماره ا & ابتدايي & مثأهل & خائهدار & at & زن & 1 \\
\hline مسجد شماره r & كارداثئ & مثأهل & بازنشسته فرهنكى & gA & مرد & r \\
\hline مسجد شماره r & ابثلايي & 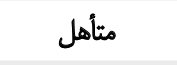 & خائهدار & ev & زن & $r$ \\
\hline مسجد شماره r & دييلم & مثتاهل & بازنشسته فرهنكي & ev & زن & $p$ \\
\hline مسجد شماره r & دييلم & مثأهل & خانهدار & v. & زن & $\Delta$ \\
\hline مسجد شماره F & كاردانى & مثأهل & بازنشسته فرهنكى & gQ & زن & $\varepsilon$ \\
\hline مسجد شماره ه & ابتلاييى & متأهل & كشاورز & $r$ & مرد & $\checkmark$ \\
\hline مسجد شماره \& & كاردانى & متأهل & بازنشسته فرهنكى & 99 & 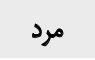 & $\wedge$ \\
\hline مسجد شماره & ابتداييى & متأهل & خانهدار & gv & زن & 9 \\
\hline مسجد شماره r & دييلم & متأهل & بازنشسته فرهنكى & gr & زن & 1. \\
\hline مسجد شماره V & كارداثئ & مثتأهل & بازْنشسته فر هنكيى & 81 & هرد & 11 \\
\hline مسجد شماره FF & كارشئاسى ارشد & متأهل & بازئشسته & 88 & هرد & ir \\
\hline مسجد شماره A & ابثدايى & مثأهل & خائهدار & v. & ن & ir \\
\hline مسجد شماره 9 & ابتدايي & متأهل & بازئشسته & qه & ن & if \\
\hline مسجد شماره - & دييلم & متأهل & بازئشسته & gr & زن & 10 \\
\hline مسجد شماره 11 & ابثلايي & بيوه & خائهدار & eq & زن & is \\
\hline مسجد شماره IT & كارشناسى & مثأهل & بازئشسته & 91 & زن & iv \\
\hline مسجد شماره با & ابتدايي & متأهل & خانهدار & ef & زن & M \\
\hline
\end{tabular}

بـ

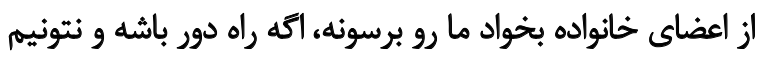

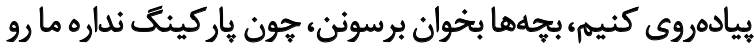

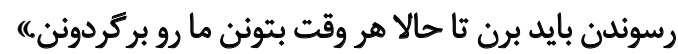

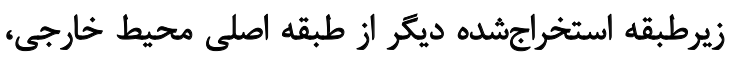

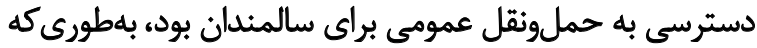

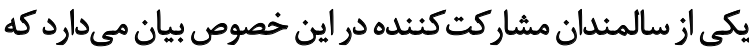

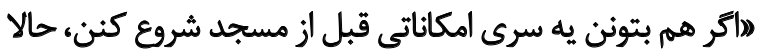

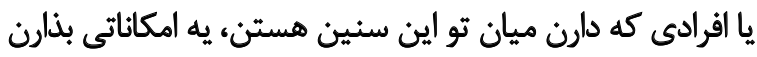

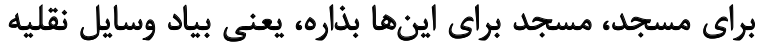

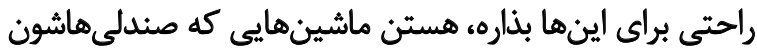

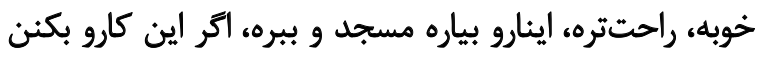

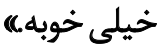

\section{طبقه الصلي دوم: محيط داخلى}

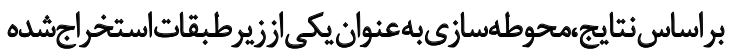

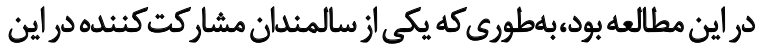

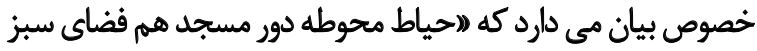

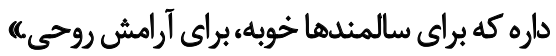

داخلى، برخوردارى از امكاثات اوليه رفاهي، تجهيزات و تسهيلات

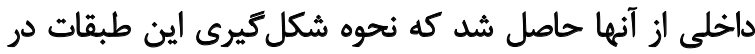

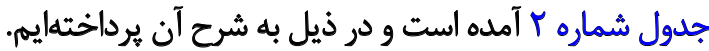

$$
\text { طبقه اصلى اول: محيط خارجى }
$$

دسترسىيذيرى به عنوان يكى از زيرطبقات استخراجشده

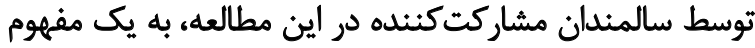

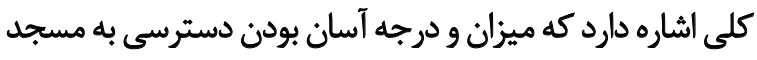

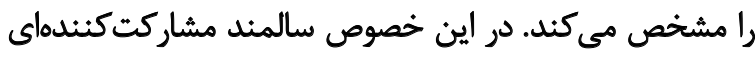

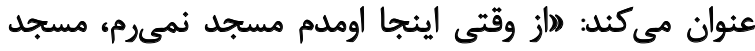

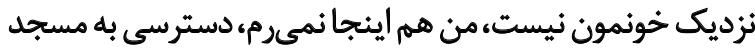

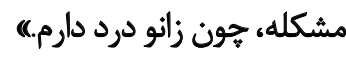

يكى ديكر از زيرطبقات استخراج شده از طبقه اصلى محيط

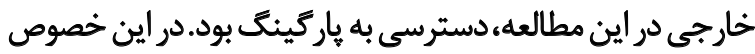

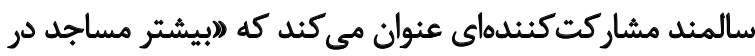

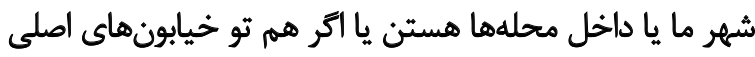

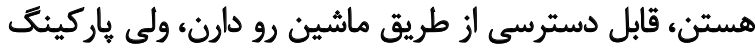

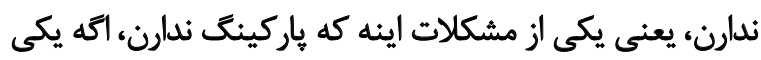


جدول r. طبقات و زيرطبقات استخراجشده از مطالعه

\begin{tabular}{|c|c|}
\hline زيرطبقات & طبقات اصلى \\
\hline 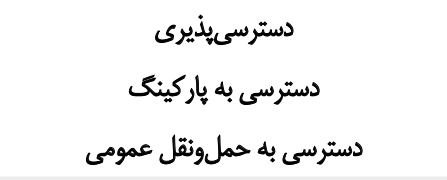 & (. محيط خارجى \\
\hline 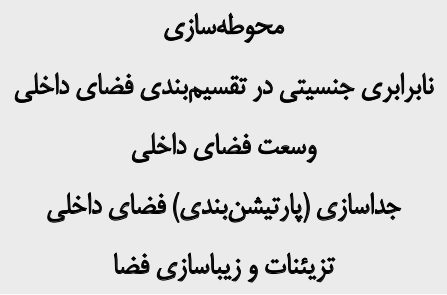 & ז. محيط داخلى \\
\hline سيستم صوتى سيستم تهويه و روشنائى & ". برخوردارى از امكانات اوليه رقاهى \\
\hline مناسبسازى ملزومات داخلى & f. تجهيزات \\
\hline 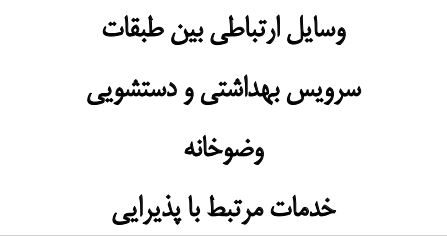 & هـ تسهيلات داخلى \\
\hline
\end{tabular}

L

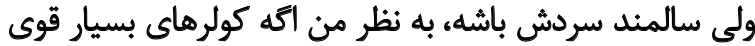

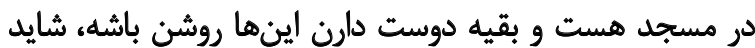

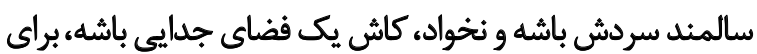

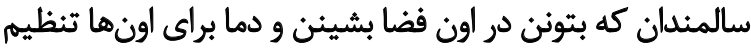

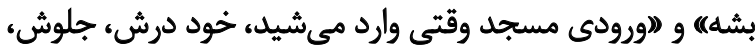

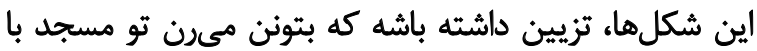

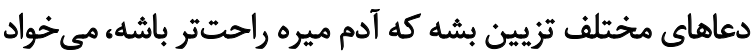

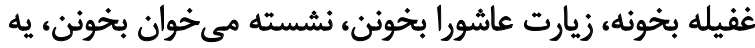

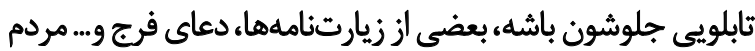

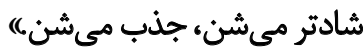

\section{طبقة اصلى سوم: برخوردارى از امكانات اوليه رفاهى}

سيستم صوتى به عنوان يكى از زيرطبقات استخراجشده،

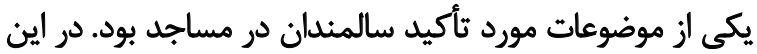

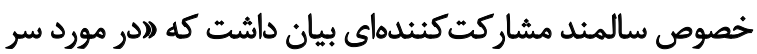

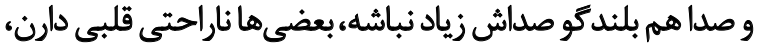

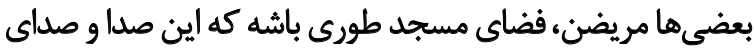

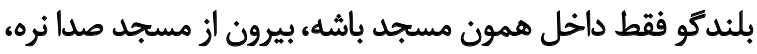

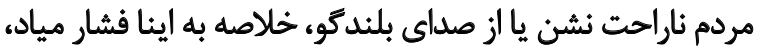

دو زيرطبقه استخراجشده ديكر از طبقه اصلى محيط داخلى

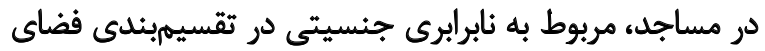

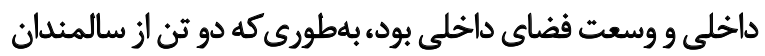

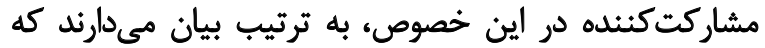

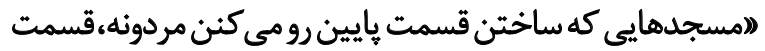

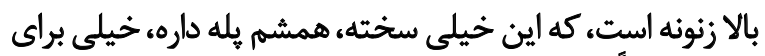

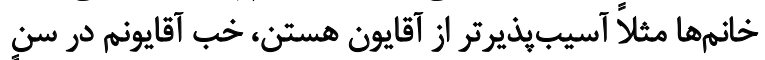

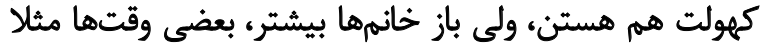

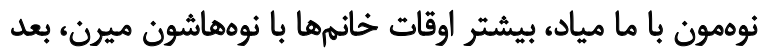

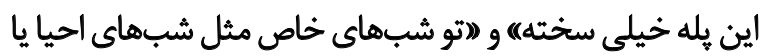

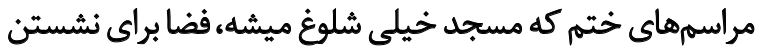

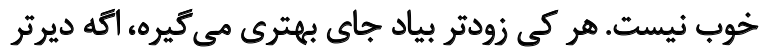

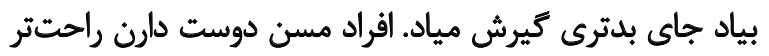

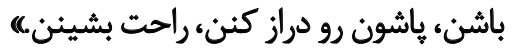
بر اساس نتايج، جداسازى (يارتيشنبندى) فضاى داخلى

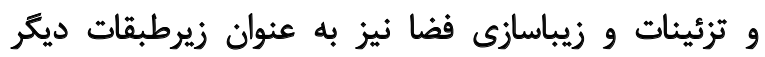

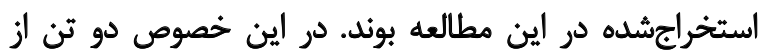

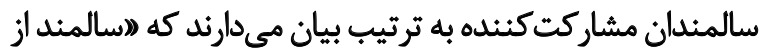

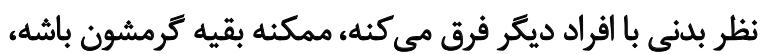




\section{طبقة اصلى ئنجمه: تسميلات داخلى}

در اين مطالعه يكى ديكر از طبقات استخراجشده بر اساس

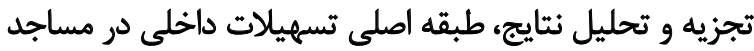

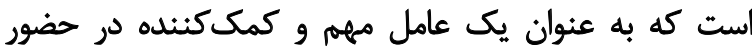

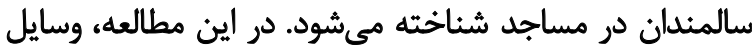

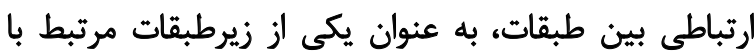

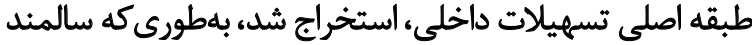

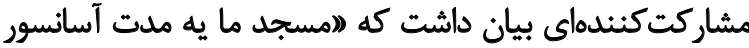

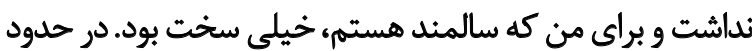

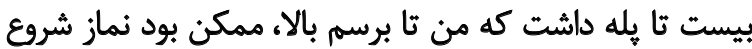

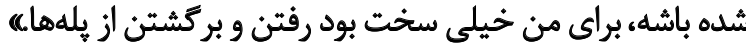
زيرطبقه ديكر استخراجشده از طبقه اصلى تسهيلات داخلى،

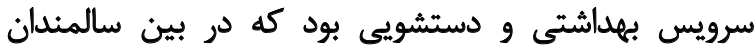

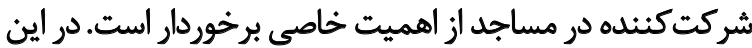

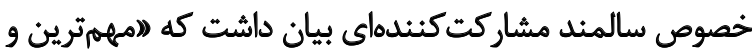
بهترين جيز براى يك سالمند به نظر من دسترسى بين به سرويس

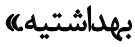

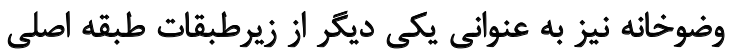

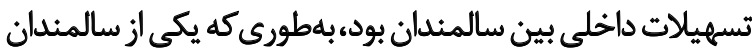

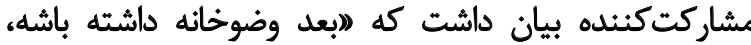

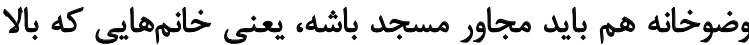

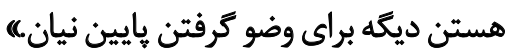

خدمات مرتبط با بذيرايى نيز به عنوان يكى ديكر از زيرطبقات،

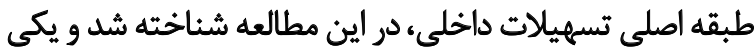

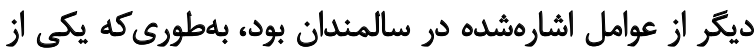

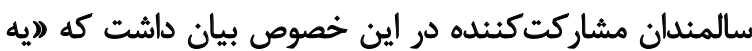

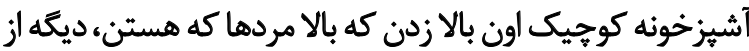

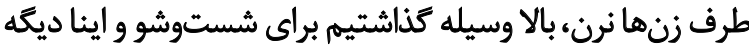

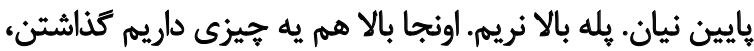

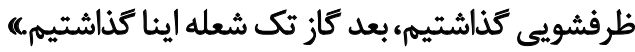

\section{بحث}

مؤلفههاى مربوط به محيط خارجى به عنوان يكى از طبقات

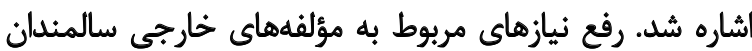

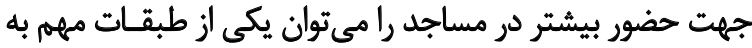

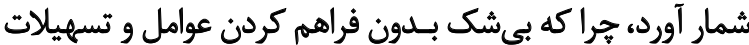

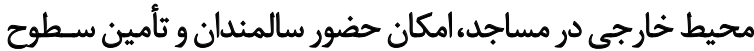

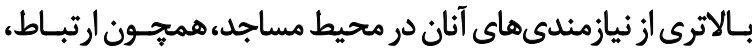

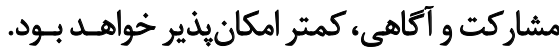

بر اساس نتايج، به با توجه به ويرگكىهاى مربوط به محيطهاى

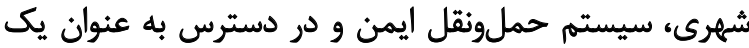

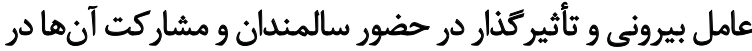

با به خاطر ناراحتى هايى كه دارن نمىتونن تحمل كنن، صداها رو بايد مراعات كنن. بهنه همجنين در اين مطالعه، يكى ديكر از زيرطبقات استخراجشده

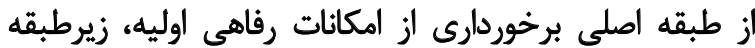

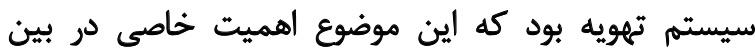

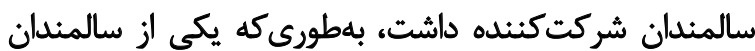

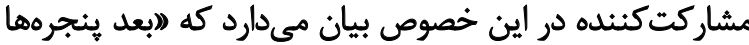

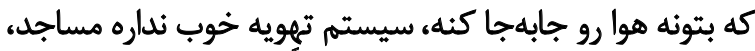

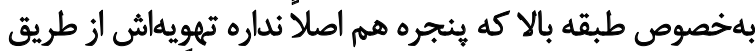

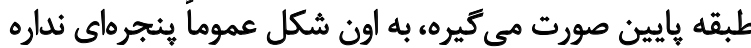

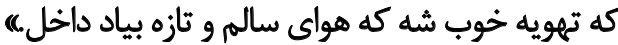
در اين مطالعه، دو زيرطبقه استخراجشده ديكر در مورد طبقه

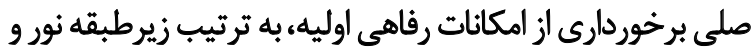

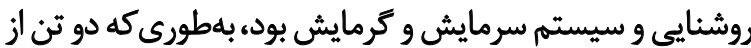

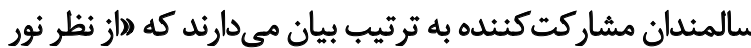

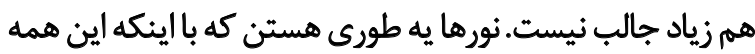

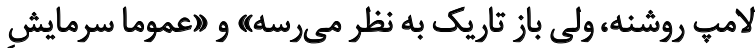

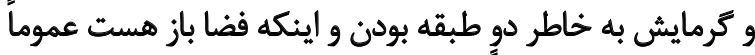

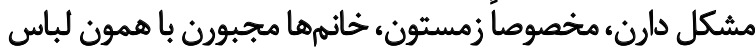

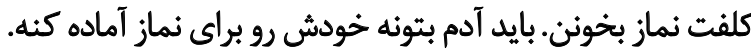

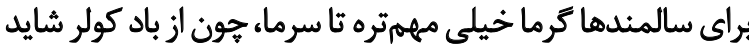

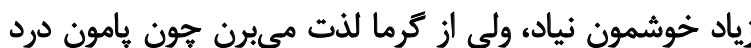

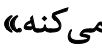

\section{طبقه اصلي همارم: تجمييزاث}

بر اساس يافتههاى اين مطالعه، تجهيزات يكى از طبقات اصلى

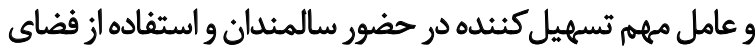

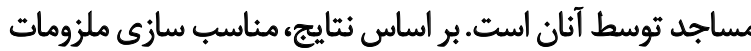

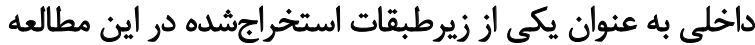

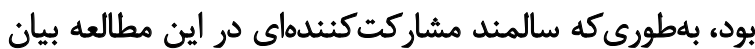

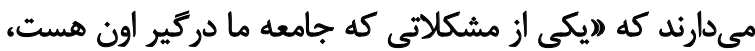

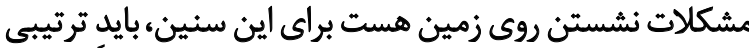

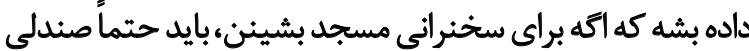

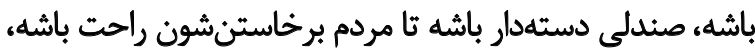

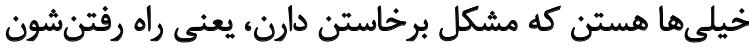

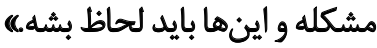

بر اساس نتايج، زيرطبقه ديكر استخراجشده در مورد طبقه

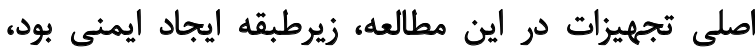

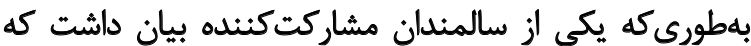

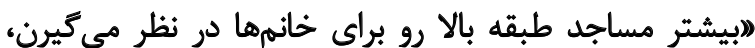

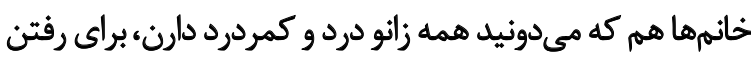

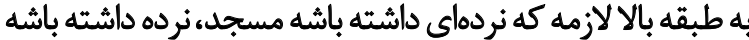

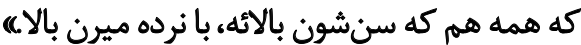


سالمند دارد و مىتوائد به افزايش حضور سالمند در فضاهاى

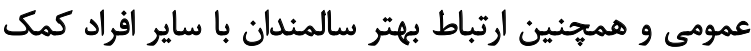

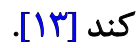

بسيارى از معيارهاى سالمندى موفق و زندكى خوب سالمثدى،

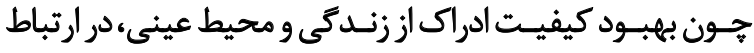

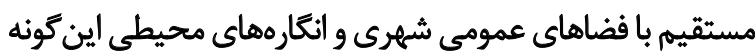

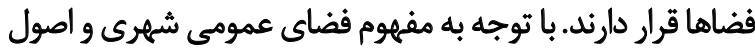

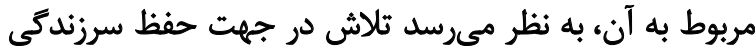

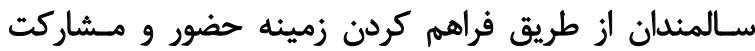

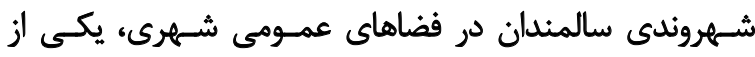

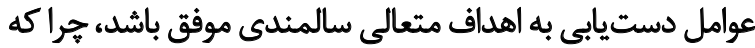

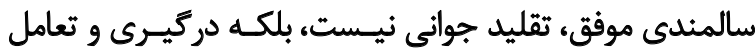

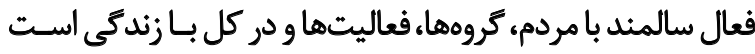

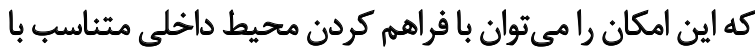

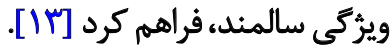

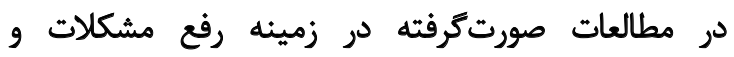

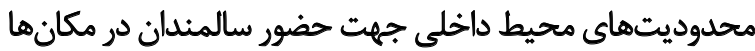

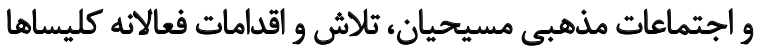

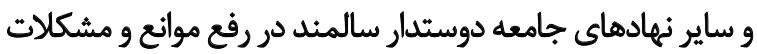

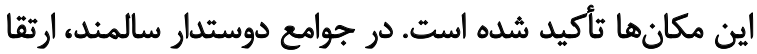

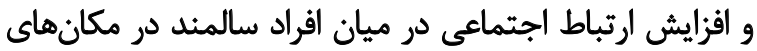

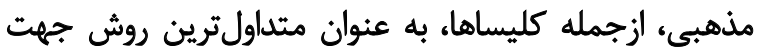

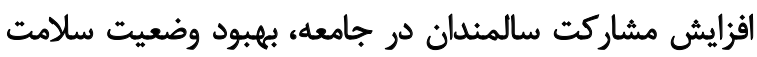

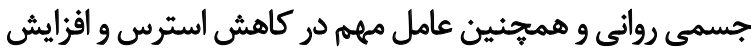

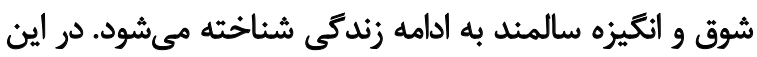

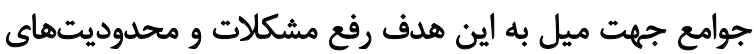

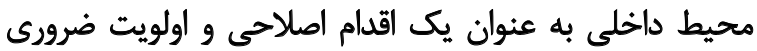

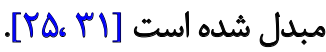

اكرجاءه توجه به تناسب ساختارى بين محيط داخلى مورد

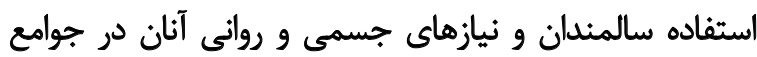

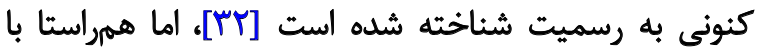

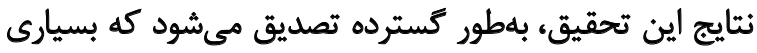

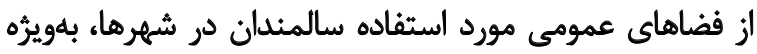

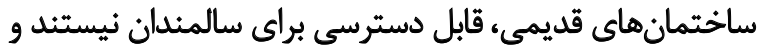

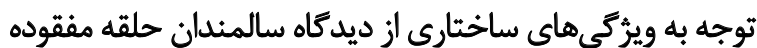

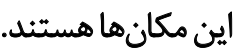

بر اساس تجزيه و تحليل يافتهها يكى از مؤلفهها كه نقش

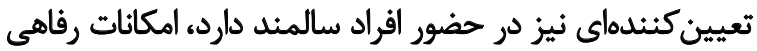

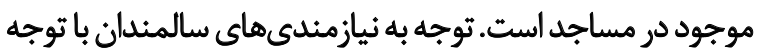

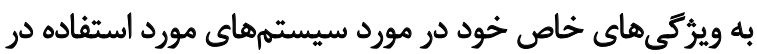

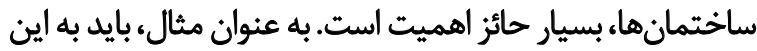

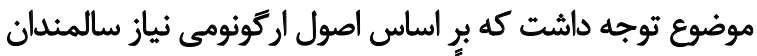

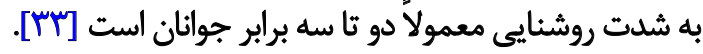

مكانهاى عمومى شهر، تلقى شده و در بررسى و ارزيابى شهرهاي

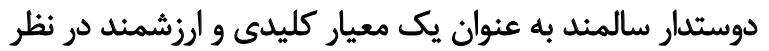

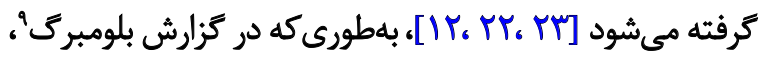

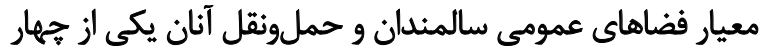

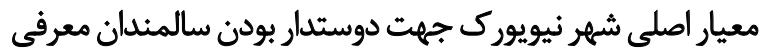

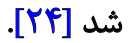

در مطالعه كيفى فيلدز روى سالمندان مراجعهكنينده به

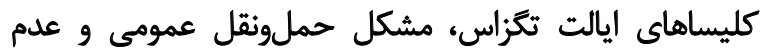

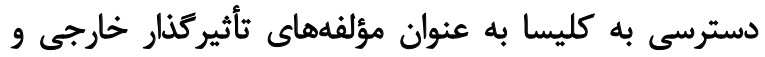

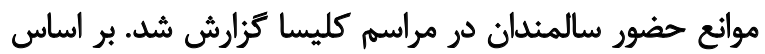

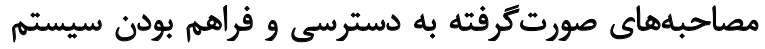

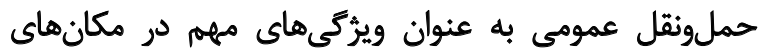

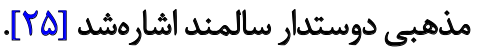

همجنين بر اساس مطالعه روف و تيريتو، ترجه سالمندان

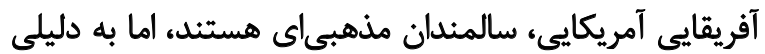

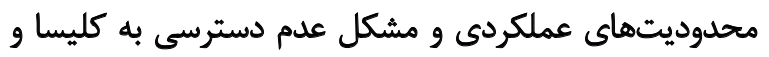

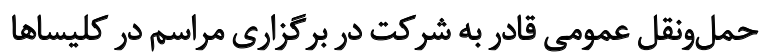

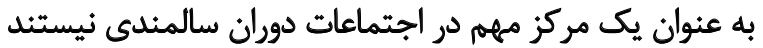

[r\%, rV]

درايران نيزمطالعه صادقىوهمكاران دسترسىواستانداردسازى

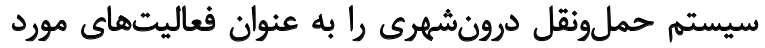

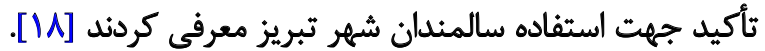

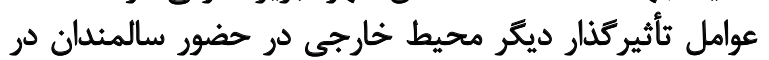

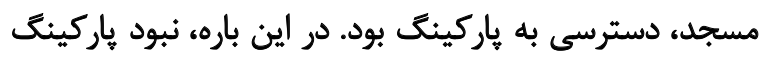

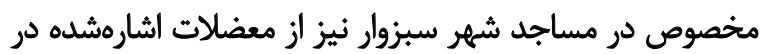

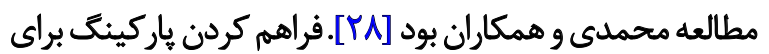

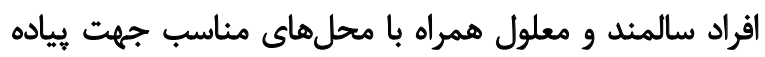

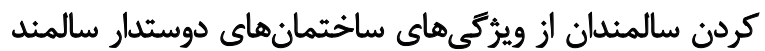

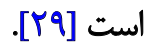

نبايد از نظر دور داشت كه تأمين خدمات و تسهيلات شهيرى

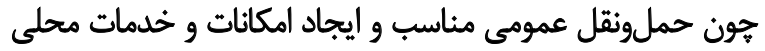

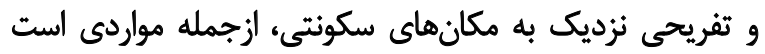

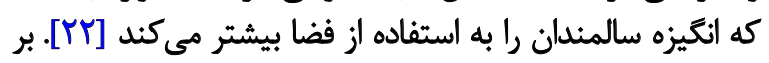

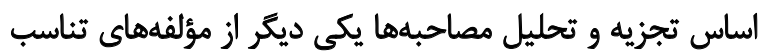

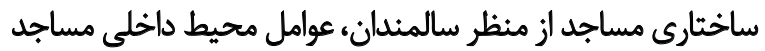

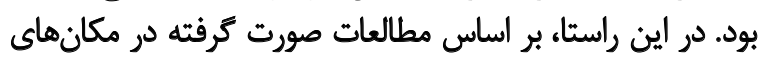

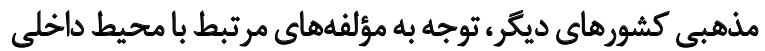

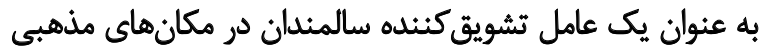

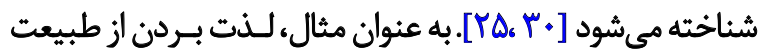

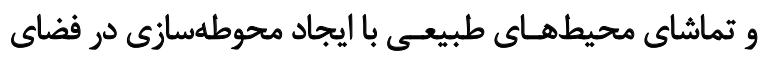

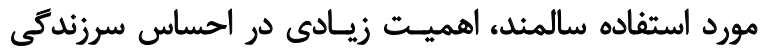

9. Bloomberg 


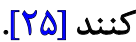
يكى ديكًر از مؤلفههاي ساختارى مساجد در اين ائروهش،

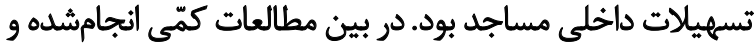

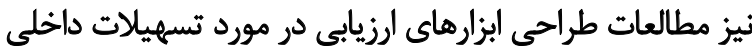

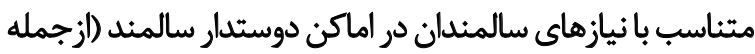

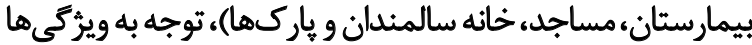

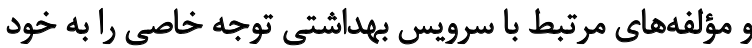

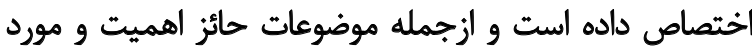

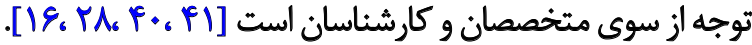

در اين خصوص ميتوان اظهار داشت كه افزايش سن با

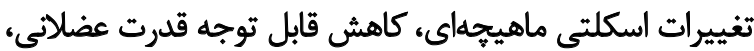

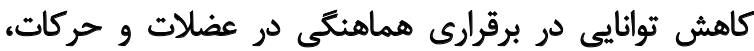

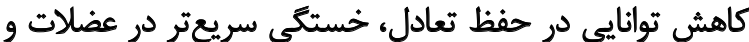

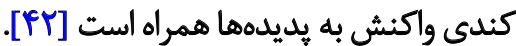

در همين راستا اختصاص جنين سهمى از توجه به به سرويسهاى بهداشتى در اماكن مورد استفاده سالمند ازئ منظر

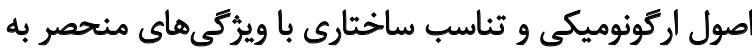

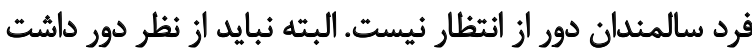

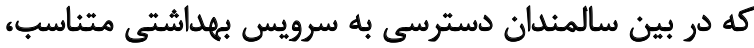

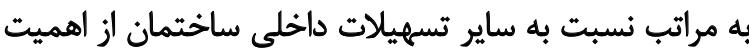

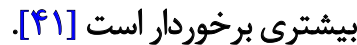

ازجمله تسهيلات داخلى يراهميت ديكرى كه سالمندان در

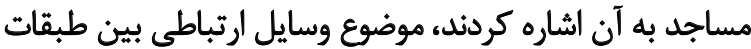

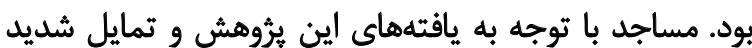

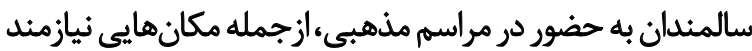

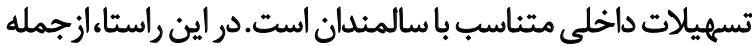

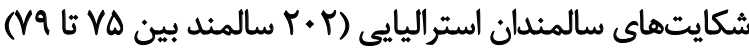

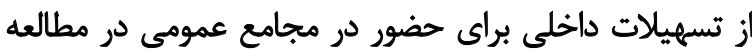

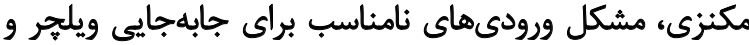

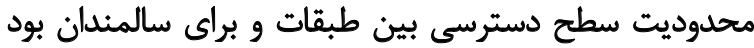

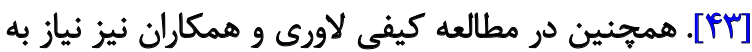

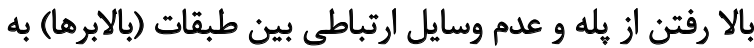

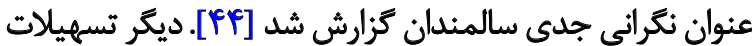

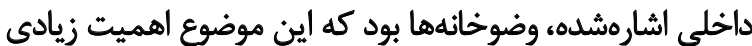

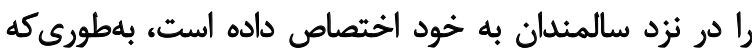
يكى از برنامههاى متثاسبسازى در مطالعه داوال و و همكاران

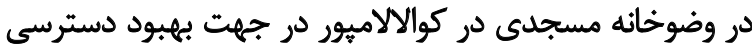

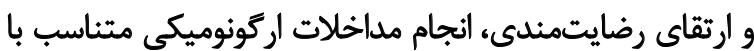

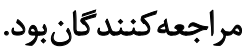
بنابر نظر سالمندان در اين مطالعه انجام اقدامات مداخلهاى

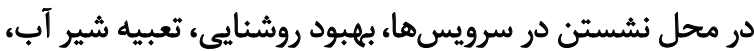

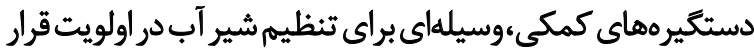

فراهمآورى شرايط آسايش حرارتى (سيستم سرمايش،

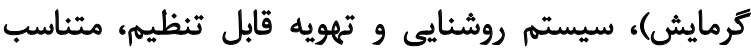

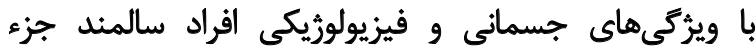

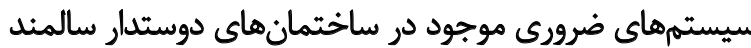

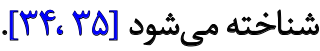
بر اساس نتايج حاصل از مطالعات انجامشده در مكانهاى

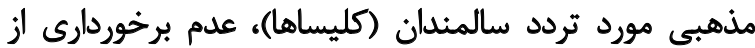

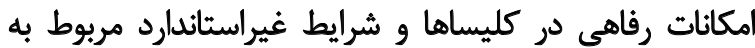

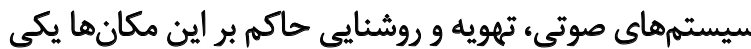

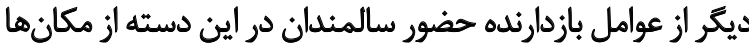

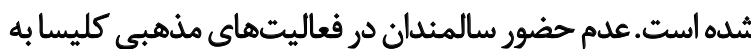

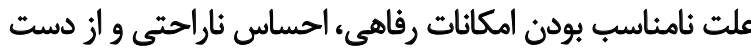

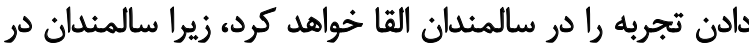

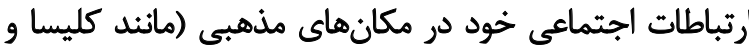

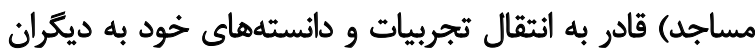

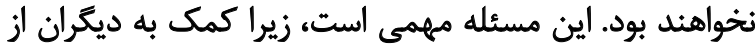

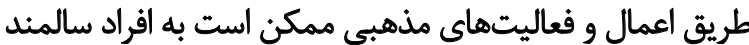

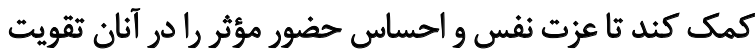

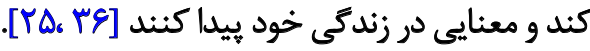

طبقه ديكر استخراجشده از مصاحبه سالمندان در مساجد،

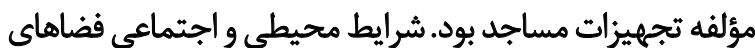

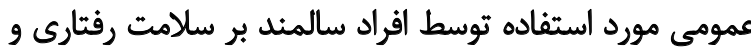

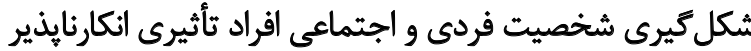

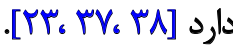

در زميئه بررسى شاخصهاى دوستدار سالمند در كشور ايران،

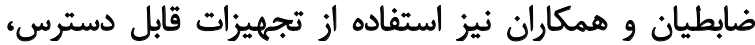

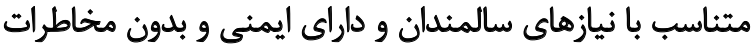

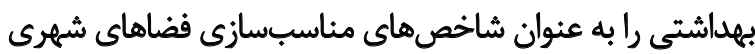

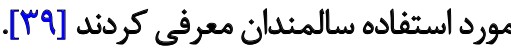
با توجه به نتايج بهدست آمده، ارزيابى نيازمندى هاى سالمندان

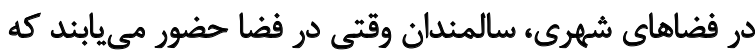

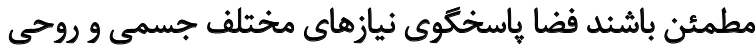

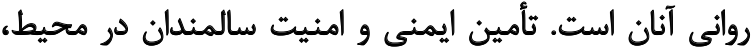

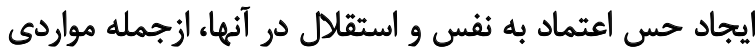

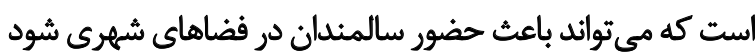

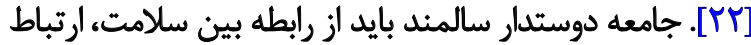

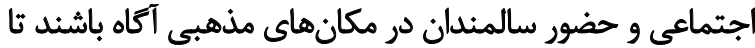

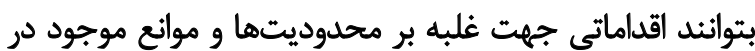

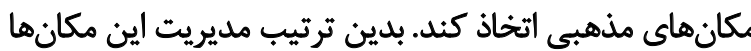

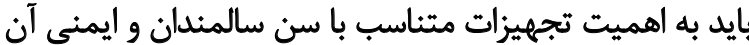

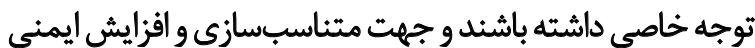
تجهيزات مورد استفاده با برنامهريزان شهرى و منطقاسئ همكارى 
ديكرى كه ممكن است با توجه به محدوديت مكان مورد تحقيق و يا موارد فرهنغى خاص اين منطقه، قابل كشف نبون نبود، به دست آيد.

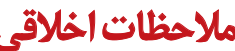

\section{يبيووى از اصول اخلاق يؤوهش}

اين يُروهش مورد تاييد كميته اخلاق دانشكاه علوم

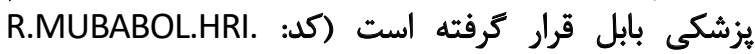

(REC.1398.324

$$
\text { هامي مالى }
$$

مطالعـه حاضــر بركرفته از قايانانامه كارشناسى ارشد

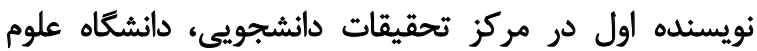
يزشكى بابل است.

مشاركت نويسند كَان

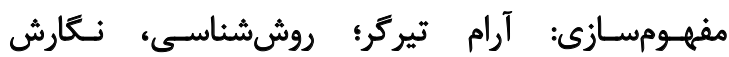

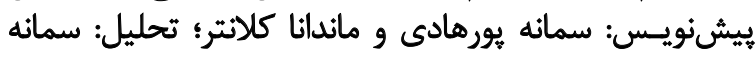
يوروهادى؛ ويراستارى نهايى: تمامى نويسندكان.

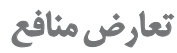

بنابر اظهار نويسندگان اين مقاله تعارض منافع ندارد

$$
\text { تشكر وقبدورأي }
$$

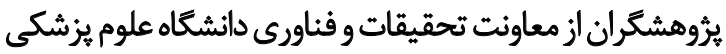

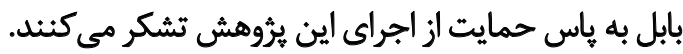

داشت [ • [ب].از طرفى شرايط نامطلوب در توالت براى نشستن فرد

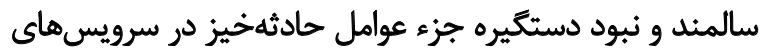

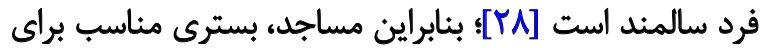

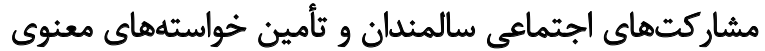

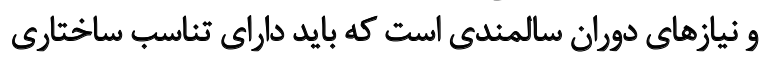

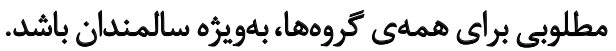

با توجه به اينكه تحقيقات مشابه در اين زمينه در ايران

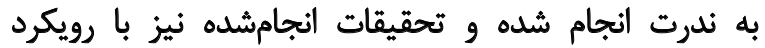

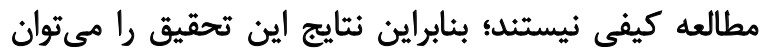

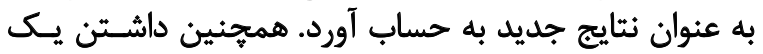

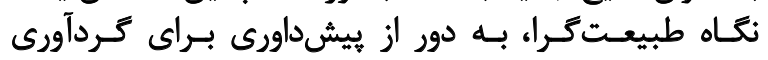

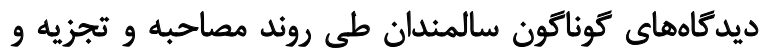
تحليل آنه، از خصوصيات مطالعه حاضـر بـهـ شــمار مــرود.

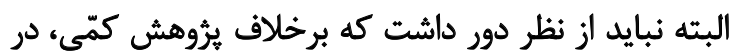

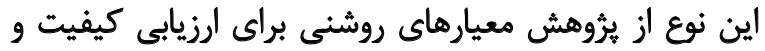

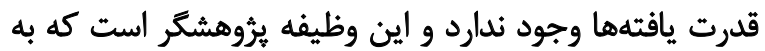

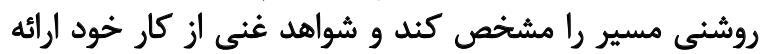

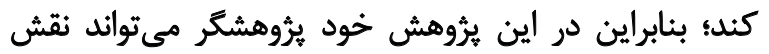

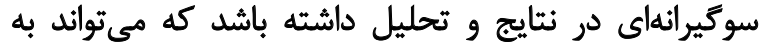

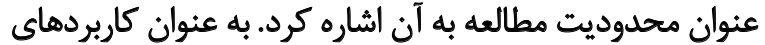

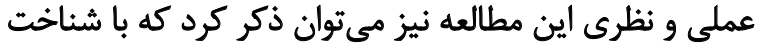

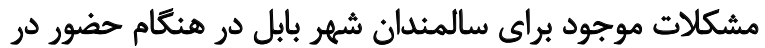

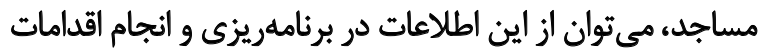
مديريتى و ايجاد شرايط بهتر برائ سارئ سالمندان و استفاده عادئلانه از خدمات استفاده كرد.

از طرف ديكر، در نظر كرفتن مؤلفههاي استخراج شده مرتبط

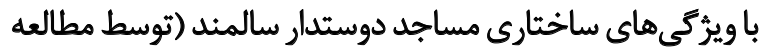

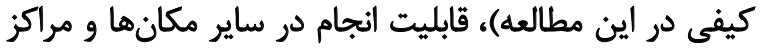

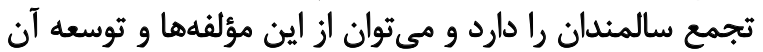

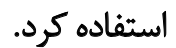

\section{نتيجهيَيرى نهايى}

اين مطالعه به تبيين ديدكاه سالمندان، بيرامون مؤلفههاى

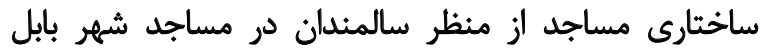

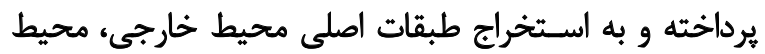

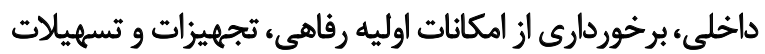

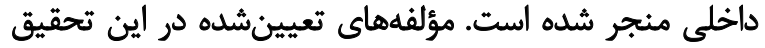

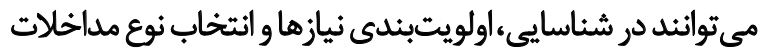

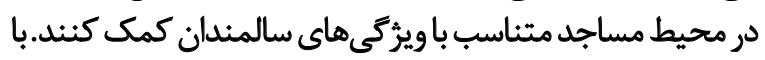

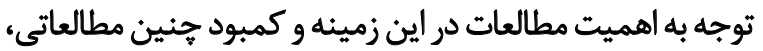

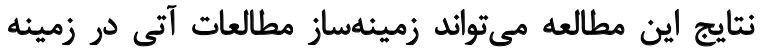

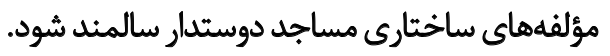
اين مطالعه را مىتوان در مناطق ديكر جهت تأييد و تكميل

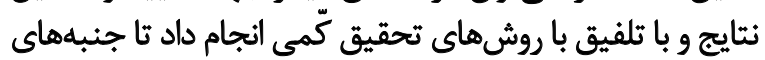




\section{Refrences}

[1] Mirzaie M, Darabi S. [Population aging in Iran and rising health care costs (Persian)]. Salmand: Iranian Journal of Ageing. 2017; 12(2):156-69. [DOI:10.21859/sija-1202156]

[2] Zhong H. The impact of population aging on income inequality in developing countries: Evidence from rural China. China Economic Review. 2011; 22(1):98-107. [DOI:10.1016/j.chieco.2010.09.003]

[3] Tanjani PT, Motlagh ME, Nazar MM, Najafi F. The health status of the elderly population of Iran in 2012. Archives of Gerontology and Geriatrics. 2015; 60(2):281-7. [DOI:10.1016/j.archger.2015.01.004] [PMID]

[4] Miri N, Maddah M, Raghfar H. [Aging and economic growth (Persian)]. Salmand: Iranian Journal of Ageing. 2019; 13(5):626-37. [DOI:10.32598/SIJA.13.Special-Issue.626]

[5] Mansour Hosseini N, Javan Forouzande A. [The role of physical-semantic components of residential public spaces in accommodating the elderly (Case study: Ekbatan residential complex) (Persian)]. Hoviatshahr. 2018; 12(1):61-74. https://hoviatshahr. srbiau.ac.ir/article_12498.html?lang=en

[6] Borhaninejad V, Shati M, Bhalla D, Iranpour A, Fadayevatan R. A population-based survey to determine association of perceived social support and self-efficacy with self-care among elderly with diabetes mellitus (Kerman city, Iran). The International Journal of Aging and Human Development. 2017; 85(4):504-17. [DOI:10.1177/0091415016689474] [PMID]

[7] Mohseni M, Iranpour A, Naghibzadeh-Tahami A, Kazazi L, Borhaninejad VR. The relationship between meaning in life and resilience in older adults: A cross-sectional study. Health Psychology Report. 2019; 7(2):133-8. [DOI:10.5114/hpr.2019.85659]

[8] Cho J, Martin P, Poon LW, Study GC. Successful aging and subjective well-being among oldest-old adults. The Gerontologist. 2015; 55(1):132-43. [DOI:10.1093/geront/gnu074] [PMID] [PMCID]

[9] Bernhold QS, Gasiorek J, Giles H. Communicative predictors of older adults' successful aging, mental health, and alcohol use. The International Journal of Aging and Human Development. 2020; 90(2):107-34. [DOI:10.1177/0091415018784715] [PMID]

[10] Stephens Ch, Flick U. Health and ageing -challenges for health psychology research. Journal of Health Psychology. 2010; 15(5):643-8. [DOI:10.1177/1359105310368178] [PMID]

[11] Jeste DV, Blazer DG, Buckwalter KC, Cassidy KK, Fishman L, Gwyther LP, et al. Age-friendly communities initiative: Public health approach to promoting successful aging. The American Journal of Geriatric Psychiatry. 2016; 24(12):1158-70. [DOI:10.1016/j.jagp.2016.07.021] [PMID]

[12] Zarghami E, Sharghi A, Olfat M. [Studying the Structural Equation Modeling (SEM) of sustainable age-friendly city indexes in Tehran (Persian)]. Journal of Sustainable Architecture and Urban Design. 2017; 5(1):61-74. https://jsaud.sru.ac.ir/article_855. $\mathrm{html}$ ?lang=en

[13] Pourjafar MR, Taghvaee AA, Bemanian MR, Sadeghi AR, Ahmadi F. [Effective environmental aspects of public spaces formation to achieve successful aging with emphasis on elderly preferences of Shiraz (Persian)]. Salmand: Iranian Journal of Ageing. 2010; 5(1):22-34. http:/ / salmandj.uswr.ac.ir/article-1-291-en.html
[14] Sadat SA, Taher Tolou Del MS. [The factors contributing to the livability of inhabitants of residential spaces (Persian)]. Journal of Sustainable Architecture and Urban Design. 2017; 5(1):47-60. https://jsaud.sru.ac.ir/article_854.html?lang=en

[15] Abdi Zarin S, Akbarian M. [Successful aging under religious believes (Persian)]. Salmand: Iranian Journal of Ageing. 2007 2(2):293-9. https://salmandj.uswr.ac.ir/article-1-7-en.html

[16] Rahmanpour MS, Tirgar A, Ebadi A, Sum Sh, Nikpour M. [Determining the components of the structural characteristics assessment tool for the age-friendly hospitals (Persian)]. Journal of Gerontology. 2019; 4(2):1-10. [DOI:10.29252/joge.4.1.1]

[17] Bastani P, Dehghani M, Ahmadi Marzaleh M. [Assessing Shiraz pharmacies according to senior-friendly criteria (Persian)]. Salmand: Iranian Journal of Ageing. 2017; 12(1):116-23. [DOI:10.21859/sija-1201116]

[18] Sadeghi F, Kaldi AR, Sahaf R. [Elderly people and their family care explanation of their experience from age-friendly city of Tabriz (Persian)]. Salmand: Iranian Journal of Ageing. 2012; 6(S1):4151. http://salmandj.uswr.ac.ir/article-1-477-en.html

[19] O'Brien BC, Harris IB, Beckman T], Reed DA, Cook DA. Standards for reporting qualitative research: A synthesis of recommendations. Academic Medicine. 2014; 89(9):1245-51. [DOI:10.1097/ ACM.0000000000000388] [PMID]

[20] Sayrs L. Interviews: An introduction to qualitative research interviewing. American Journal of Evaluation. 1998; 19(2):267-70 [DOI:10.1177/109821409801900217]

[21] Rezapour Nasrabad R. [Criteria of validity and reliability in qualitative research (Persian)]. Journal of Qualitative Research in Health Sciences. 2017; 6(4):493-9. http://jqr1.kmu.ac.ir/article $91112 \mathrm{html}$

[22] World Health Organization. Global age-friendly cities: A guide [Internet]. 2007 [Updated 2007]. Available from: https:// www.who.int/ageing/publications/Global_age_friendly_cities_Guide_English.pdf

[23] Steels S. Key characteristics of age-friendly cities and communities: A review. Cities. 2015; 47(1):45-52. [DOI:10.1016/j.cities.2015.02.004]

[24] Office of the Deputy Mayor for Health and Human Services. Age-friendly NYC: Enhancing our city's livability for older New Yorkers. New York: Council of the City of New York; 2009. https://books.google.com/books?id=icryngEACAAJ\&dq

[25] Fields NL, Adorno G, Magruder K, Parekh R, Felderhoff BJ Age-friendly cities: The role of churches. Journal of Religion, Spirituality \& Aging. 2016; 28(3):264-78. [DOI:10.1080/15528030.2016 .1155526]

[26] Roff LL, Klemmack DL, Simon C, Cho GW, Parker MW, Koenig $\mathrm{HG}$, et al. Functional limitations and religious service attendance among african american and white older adults. Health \& Social Work. 2006; 31(4):246-55. [DOI:10.1093/hsw/31.4.246] [PMID]

[27] Tirrito T, Spencer-Amado J. Older adults' willingness to use social services in places of worship. Journal of Religious Gerontology. 2000; 11(2):29-42. [DOI:10.1300/J078v11n02_03]

[28] Mohammadi Z, Tirgar A, Sum Sh. [Assessment of the suitability of the structure of mosques in the light of the elderly's needs (Persian)]. Journal of Pizhūhish dar dīn va Salāmat. 2018; 4(2):94 104. [DOI:10.22037/jrrh.v4i2.19475] 
[29] Plouffe L, Kalache A. Towards global age-friendly cities: Determining urban features that promote active aging. Journal of Urban Health. 2010; 87(5):733-9. [DOI:10.1007/s11524-010-9466-0] [PMID] [PMCID]

[30] Dawal SZ, Mahadi WNL, Mubin M, Daruis DDI, Mohamaddan Sh, Abdul Razak FA, et al. Wudu'workstation design for elderly and disabled people in Malaysia's mosques. Iranian Journal of Public Health. 2016; 45(S1):114-24. https:/ /ijph.tums.ac.ir/ index.php/ijph/article/view/6163/0

[31] Cnaan RA, Boddie SC, Kang JJ. Religious congregations as social services providers for older adults. Journal of Gerontological Social Work. 2005; 45(1-2):105-30. [DOI:10.1300/J083v45n01_07] [PMID]

[32] Fitzgerald KG, Caro FG. An overview of age-friendly cities and communities around the world. Journal of Aging \& Social Policy. 2014; 26(1-2):1-18. [DOI:10.1080/08959420.2014.860786] [PMID]

[33] Zhou YY, Zhu WD. Study on subjective evaluation of comfort of lighting environment in nursing institutions. Applied Mechanics and Materials. 2016; 858:262-6. [DOI:10.4028/www.scientific. net/AMM.858.262]

[34] Luciano A, Pascale F, Polverino F, Pooley A. Measuring agefriendly housing: A framework. Sustainability. 2020; 12(3):848. [DOI:10.3390/su12030848]

[35] James B, Saville-Smith K, Jaques R. Tools for good homes for ageing in place. Paper presented at: 6th Australasian Housing Researchers' Conference. 8-10 February 2012; Adelaide, South Australia. https:/ / www.researchgate.net/publication/292834425

[36] Crowther MR, Parker MW, Achenbaum WA, Larimore WL, Koenig HG. Rowe and Kahn's model of successful aging revisited: Positive spirituality- The forgotten factor. The Gerontologist. 2002; 42(5):613-20. [DOI:10.1093/geront/42.5.613] [PMID]

[37] Lean OK, Zailani S, Ramayah T, Fernando Y. Factors influencing intention to use e-government services among citizens in Malaysia. International Journal of Information Management. 2009; 29(6):458-75. [DOI:10.1016/j.ijinfomgt.2009.03.012]

[38] Fässberg MM, van Orden KA, Duberstein P, Erlangsen A, Lapierre S, Bodner E, et al. A systematic review of social factors and suicidal behavior in older adulthood. International Journal of Environmental Research and Public Health. 2012; 9(3):722-45. [DOI:10.3390/ijerph9030722] [PMID] [PMCID]

[39] Zabetian E, Taghvaei AA. [Elderly friendly cities through people participation (Persian)]. Journal of Housing and Rural Environment. 2009; 28(128):60-71. http:/ /jhre.ir/article-1-53-en.html

[40] Rashmi MR, Kasthuri A, Rodrigues R. Senior friendly hospitals: Development and application of criteria: A descriptive study. Indian Journal of Community Medicine. 2016; 41(4):256-62. [DOI:10.4103/0970-0218.193334] [PMID] [PMCID]

[41] Zarghami E, Sharghi A, Olfat M. [Environmental features affecting the quality of life among elderly residents in nursing homes, case study: Shemiranat area in Tehran province (Persian)]. Journal of Iranian Architecture Studies. 2015; 4(7):111-26. http:/ / jias.kashanu.ac.ir/article-1-708-en.html

[42] Rahmanpour MS, Ebadi A, Tirgar A. [The necessity of ergonomic considerations in accreditation of hospitals with emphasize on elderly features (Persian)]. Iranian Journal of Ergonomics. 2018; 6(3):1-10. [DOI:10.30699/jergon.6.3.1]
[43] Mackenzie L, Curryer C, Byles JE. Narratives of home and place: Findings from the housing and independent living study. Ageing \& Society. 2015; 35(8):1684-712. [DOI:10.1017/ S0144686X14000476]

[44] Lavery AL. Aging in place: Perceptions of older adults on low income housing waitlists [PhD. dissertation]. Denver, CO: University of Denver; 2015. https://digitalcommons.du.edu/ etd/356/ 